\title{
Review on Analysis of Gene Expression Data Using Biclustering Approaches
}

\author{
S. Anitha and Dr.C.P. Chandran
}

\begin{abstract}
In this paper, survey on biclustering approaches for Gene Expression Data (GED) is carried out. Some of the issues are Correlation, Class discovery, Coherent biclusters and coregulated biclusters. Each table entry is called an expression value and reflects the behaviour of the gene in a row in the situation in column. The goal of biclustering is to identify "homogeneous" submatrices. Given a gene expression data matrix $D=G \times C=\left\{d_{i j}\right\}$ (here i $€[1, n]$, $j \in[1, m])$ is a real-valued $n \times m$ matrix, here $G$ is a set of $n$ genes $\left\{g_{1}, g_{2} \ldots, g_{n}\right\}, C$ a set of $m$ biological conditions $\{c l$, $\left.c 2 \ldots, c_{n}\right\}$.
\end{abstract}

\section{INTRODUCTION}

$\mathrm{G}$ ENE expression is the process by which information J from a gene is used in the synthesis of a functional gene product [1]. The various steps in gene expression process are transcription, RNA splicing, translation, and post-translational modification of a protein [2]. The process of gene expression occurs in both prokaryotes and eukaryotes. Transcription is a process in which the DNA is converted into RNA. The production of RNA copies of the DNA is called transcription. The transcription process is carried out by the enzyme RNA polymerase. In the prokaryotes, the transcription is carried out by a single type of RNA polymerase.

In eukaryotes, three types of RNA polymerases such as RNA polymerase I, RNA polymerase II and RNA polymerase III are involved. RNA splicing is a very important modification of eukaryotic pre m-RNA. The eukaryotic pre mRNA consists of alternating segments called exons and introns. RNA splicing is a process in which introns are removed and then exons are joined together. It normally resides on a stretch of DNA that codes for a type of protein or for an RNA chain that has a function in the organism A GED is described as a table with ' $\mathrm{n}$ ' rows corresponding to genes and ' $\mathrm{m}$ ' columns corresponding to situations [3].

\section{GENE EXPRESSION DATA}

\section{A. Class Discovery}

Class Discovery from GED identifies coherent patterns known as scaling and shifting patterns from high dimensional Gene Expression datasets. Shifting pattern is defined as the expression values vary in the addition of a fixed value for all the genes. Scaling pattern is defined as the expression values vary in the multiplication of a fixed value for all the

S. Anitha, Research Scholar Ph.D(Part-Time Category B), Bharathiar University, Coimbatore.E-mail:anithashanoi@gmail.com

Dr.C.P. Chandran, Associate Professor, Computer Science, Ayya Nadar Janaki Ammal College, Sivakasi. E-mail:drcpchandran@gmail.com DOI: 10.9756/BIJDM.8135
genes.Wang et. al., [4] proposed a model of discovering pattern based clusters by considering the scaling and shifting patterns formed by similar genes and conditions under pCluster model and pair-wise clustering by finding maximum dimension set. Jian Pei et. al., [5] have proposed a maximal pattern based biclustering model MaPle, which conducts a depth-first, divide-and-conquer search and prunes unnecessary branches. A deterministic biclustering model for gene expression data is proposed by Lizhuang Zhao et. al., [6] named as Micro Cluster. They have used weighted, directed multi graph for finding the patterns formed by sub set of genes and conditions.

Wen-Hui Yang et. al., [7] proposed a method to find the correlated biclusters from gene expression data using a mixed clustering algorithm which discovers gene subsetand experimental conditions positive and negative correlations. Alan Wee-Chung Liew [8] developed a greedy version of pCluster algorithm. They can identify both additive-related and multiplicative-related biclusters in the presence of overlap and noise. They have also provided a PC plot visualization tool for biclusters. A CE-Tree method for finding pClusters has been proposed by Jiun-Rung Chen et. al., [9]. In thid method insted they expand the CE-Tree in local-breadth-first within global depth-first manner to efficiently find all pClusters. Amir BenDory [10] proposed an overabundance analysis assessing how informative a given expression dataset is with respect to a partition of the samples.

Nir Friedman said that Naive Bayesian Classification used to statistically scoring candidate partitions according to the overabundance of genes that separate the different classes and then use the simulated annealing we explore the space of all possible partitions of the set of samples, seeking partitions with statistically significant overabundance of differentially expressed genes [11].

Gaasenbeek [12] conveyed that a Self-Organization Map (SOM) the user specifies the number of clusters to be identified. The SOM finds an optimal set of centroids around which the data points appear to aggregate. It then partitions the dataset, with each centroid defining a cluster consisting of the data points nearest to it. Jeff Solka [13] conveyed that Gene Latent Class Discovery that reside undiscovered within a known class of observations. And develop a general methodology for the discernment of latent class structure during discriminate analysis. Nikhil Ranjan Pal [14] proposed a Fuzzy Clustering Algorithm (FCA) to cluster the data set in the reduced dimension to extract prototypes for each class. Then these prototypes are used to generate set of fuzzy rules which is then refined to improve the classifier performance. Xuegong Zhang [15] conveyed that new approach to cancer 
classification based on gene expression monitoring by DNA microarrays and to evaluate the correlation of each gene to the classification. After some good genes were selected from all the 6817 genes, the classification is done by a weighted voting scheme. Chun Tang [16] conveyed that gene analysis algorithm to a visualization tool based on this mapping method. It is used to monitor and analysis procedure, to adjust parameters dynamically, and to evaluate the result of each step. Michael O'Connell [17] proposed an new approach called $\mathrm{S}+$ Arrray Analyzer used to find the different expressed genes in three populations of immune exposure: naïve (no exposure), 48 hour activated, and CD8+ T-cell clone D4 (longterm mild exposure). Peng Qiu[18] conveyed that SPectral Analysis for Class discovery and Classification (SPACC), used to train the samples are nodes of an undirected weighted network. Uri Einav[19] proposed that a new technique called as FISH . Florescence-In-Situ-Hybridization uses fluorescent DNA probes that hybridize to specific portions of chromosomes. Tibshirani et. al,. [20] Proposed that new technique called as supervised microarray data analysis methods by developing the nearest shrunken centroid method, also known as PAM. This technique not only allows predicting of classes, but also tries to limit the number of genes necessary to make the prediction. By limiting the number of genes, it is possible to develop cheaper methods to make a diagnostic test, such as smaller microarrays or quantitative PCR.

\section{B. Coherent Biclusters}

A bicluster with coherent values is the subset of genes and subsets of conditions on both rows and columns. Genes involved in common process are often co-expressed. It is used to expression level of a group of co-expressed genes. A group of co-expressed genes exhibits a common expression pattern. Bloch et al., demonstrated [21] that Divisive Coherent Clustering Algorithm (DCCA) used to display the Pearson's coherent as the similarity measure. S. Sarmah[22] developed an genclus method to measure the coherence of a neuron. Bhattacharyya is developed [23] nontrivial coherent method used to measure the coherent biclusters in the gene expression data. Valarmathie has developed [24] Coherent method used to the identification of groups of genes with coherent expression. X. Fei et. al., is developed [25] a Genetic Fuzzy biclustering algorithm used to identify the value coherent biclusters. Tang e.t al., [26] introduced a framework for unsupervised analysis of GED which applies an interrelated two-way clustering approach on the gene expression matrices. Kluger et. al., [27] proposed a method to discover the biclusters with coherent values and looked for checkerboard structures in the data matrix by integrating biclustering of rows and columns with the Normalization the data matrix. Busy gin et. al., [28] proposed another an approach called Double Conjugated Clustering (DCC) which aimed to discover biclusters with coherent values defined using multiplicative model of biclusters. Dhollander et. al., [29] introduced a model-based query-driven module discovery tool QDB, but it is aimed at performing informed biclustering instead of pattern matching, and it does not take into account the complex correlation patterns such as inverse patterns. Owen et. al., [30] proposed a score-based search algorithm called Gene Recommender (GR) to find genes that are co expressed with a given set of genes using data from large microarray datasets. GR first selects a subset of experiments in which the query genes are most strongly co-regulated. Hence multiple query genes are required. Hu et. al., [31] developed model based gene expression query algorithm BEST (Bayesian Expression Search Tool) built under the Bayesian model selection framework. It is capable of detecting coexpression profiles under a subset of samples/experimental conditions. Bagyamani and Thangavel [32] developed that an SIMBIC algorithm is an improvement of MSB in terms of computational efficiency but the biclusters obtained by both the methods are same. Instead of single row column deletion, multiple rows columns are deleted. Sungroh Yoon [33] conveyed that a zero-suppressed binary decision diagrams have been used in other domains, namely Computer Aided Design and VLSI used to incorporate the instances of an gene expression data. Rathipriya [34] has proposed an MAXBIC+ biclustering technique uses bottom up approach to extract two biclusters at a time with different objectives based on the query gene. Rathipriya, Thangavel and Bagyamani [35] conveyed that an Seed Enlargement and Refinement using Greedy Search Procedure seeds are enlarged and refined by adding /removing the rows and columns to enlarge their volume and improve their quality respectively. The main goal of the greedy search procedure is to maximize the volume of the biclusters seed without degrading the quality measure. chagang [36] conveyed that new technique called Parallel Biclustering Algorithm(PCA) to uncover all valid biclusters with coherent evolutions in each set of data and differential analysis on the set of biclusters identified in step one, yielding sets of convergent, divergent, partially conserved and split conserved biclusters. It includes a pre-processing step, starts with a data conditioning routine to deal with the noise in the DNA microarray data as well as missing values. Aguilar-Ruiz [37] conveyed that a Hartigan's algorithm, named direct clustering, divides the data matrix into a certain number of biclusters, with the minimum variance value, so the fact of finding a number of sub-matrices equal to the number of elements of the matrix is avoided. Another way of searching biclusters is to measure the coherence between their genes and conditions. Cesim Erten[38] conveyed that LEB (Localizeand-Extract Biclusters) which reduces the search space into local neighborhoods within the matrix by first localizing correlated structures. Anirban Mukhopadhyay [39] saved that a new technique called Flexible Overlapped biClustering (FLOC) begins with a initial set of biclusters (seeds) and iteratively improves the overall quality of the biclustering, at each iteration, each row and column is moved among the biclusters to yield a better biclustering in terms of lower MSR the best biclustering obtained during iteration is used as the initial biclustering seed in the next iteration. The algorithm terminates automatically when the current iteration fails to improve the overall biclustering quality. Thus FLOC is able to evolve k biclusters simultaneously. Gaurav Pandey [40] saved that a novel association analysis framework for exhaustively and efficiently mining "range support" patterns from such a data set. On one hand, this framework reduces the loss of information incurred by the binarization- and discretizationbased approaches, and on the other, it enables the exhaustive discovery of coherent biclusters. Hua-Sheng Chiu [41] saved 
that new technique called as Biclustering by Iterative Genetic Algorithm (BIGA) approach is proposed to identify transcriptional module (TM) in gene expression data, avoiding the intrinsic limitations of the heuristic biclustering algorithms. Peter A. DiMaggio [42] saved that a new technique called as OREO, which is based on the Optimal REOrdering of the rows and columns of a data matrix. This optimal re-ordering model is used in an iterative framework where cluster boundaries in one dimension are used to partition and re-order the other dimensions of the corresponding submatrices. Andre V. Carreiro[43] saved that an new technique called as CCC-Biclustering was integrated in new biclustering-based classifiers for prognostic prediction. Sanghamitra Bandyopadhyay [44] saved that, a new coherence measure called Scaling Mean Squared Residue (SMSR) is proposed and a new measure is able to detect the scaling patterns effectively and it is invariant to local or global scaling of the input dataset.

\section{Coregulated Biclusters}

Coregulated biclusters are also often functionally associated, and such Apriori known or pre-computed associations can provide support for appropriately grouping genes. It is a measure of that describes a particular type of association between two genes. It is also the basis of several clustering methods. Most commonly used correlation statistic is Pearson Correlation Coefficient (PCC) which includes the measure to identify the coregulated bicluster, counts the number of times each gene in the same cluster. It is used to analyse the co-regulation between pairs of genes. It is a measure of that describes a particular type of association between two genes. Zhang et. al.,[45] proposed the TimeSeries Biclustering algorithm (CC-TSB algorithm), restricting it to add and/or remove only columns that are contiguous to the partially constructed biclusters, thus forcing the resulting biclusters to have only contiguous columns.. David J. Reiss[46] is developed cMonkey, which detects putative co-regulated gene groupings by integrating the biclustering of gene expression data and various functional associations with the de nov $\mathrm{Xu}$ [47] conveyed that reg-cluster model, to identify all tha significant Shifting-and-Scalling co-regulation patterns. Dharan and Achuthsankar have demonstrated [48] that GRASP approach starts from small high quality biclusters seeds, which are tightly coregulated submatrices of the gene expression matrix. These seeds are further enlarged by adding more rows and columns to them. Bhattacharya and Raja [49] is propose a new technique on Bi-Correlation Clustering Algorithm (BCCA) produces an diverse set of biclusters of coregulated genes over a subset of samples where all the genes in a biclusters as Have a similar change of expression pattern over the subset of samples. Zhang and Zhan [50] applied a new technique on Time-Series Biclustering (CC-TSB) used to discover co regulated genes that show similar expression profiles in certain sub-interval. Remanding [51] is developed a coregulated based model used to clear relationship between the network structures. Cheng [52] says that BiVisu is an open-source software tool for detecting and visualizing biclusters embedded in a gene expression matrix and display the co -regulated genes that clustering methods in which partition data based on whole set of genes or conditions, biclustering groups a subset of genes (rows) over a subset of conditions (columns). Genes which are co-regulated under certain biological processes can be identified. Peter Waltman[53] says that multiple-species datasets in order to identify conserved modules and the conditions under which these modules are active. The advantages of this method are that conserved modules are more likely to be biologically significant than co-regulated gene groups lacking detectable conservation, and the identification of these conserved modules can provide a basis for investigating the evolution of gene regulatory networks.

\section{Correlated Biclustering}

Correlation biclusters describes a particular type of association between two genes. It is also the basis of several clustering methods. The most commonly used correlation statistic is Pearson's linear correlation coefficient, r. It has a maximum value of one when two variables such as the expression levels of two genes in various tissues are exactly linearly proportional. Correlation coefficients value is near 1 , 0 , and -1 . Correlation is a measure that describes a particular type of association between two genes. The most commonly used correlation statistic is Pearson Correlation Coefficient (PCC) and then maximum value of one when two variables. Remondini [54] says that correlation based model used to clear the relationship between network structures. Karen Bloch and Gonzalo Acre [55] is applied a Non linear correlation technique used to displayed as the data on the median correlation. Nurual Haque Moclah [56] is demonstrated a Robust Correlation technique used to minimum the $\beta$-divergence based on robust correlation matrix. Lindl [57] said that an cloud correlation-based methods means that the computational cost is reduced, since only N/2 correlations have to be computed for a data set of $\mathrm{N}$ expression profiles. Peter Larsen, Eyad Almasri[58] saved that Correlated Discredited Expression (CDE) score calculated from microarray time course data. The CDE-score is derived by discrediting microarray data to identify significant gene expression changes. Ankit Agrawal, and Ankush Mittal[59] says that an Dynamic Time-Lagged Correlation Based Method (DTCBM) to learn the gene networks, which uses time-lagged correlation to find the potential gene interactions, and then uses a post-processing stage to remove false gene interactions to common parents, and finally uses dynamic correlation thresholds for each gene to construct the gene network. DTCBM finds correlation between gene expression signals shifted in time, and therefore takes into consideration the multi time delay relationships among the genes. Juan A Nepomuceno and Alicia Troncoso[60] proposed an Scatter Search is an evolutionary technique that is based on the evolution of a small set of solutions which are chosen according to quality and diversity criteria. Scatter Search uses strategies to diversify and intensify the search in order to avoid local minima and to find quality solutions and, on the opposite of other evolutionary heuristics, it emphasizes systematic processes against random procedures. Feng $\mathrm{He}$ and An-Ping Zeng [61] says that PCC clustering method treats its input as a vector of independent samples and hence doesn't take into account the temporal relationship between consecutive time points. Nurul Haque Mollah[62] proposed an 
robust if hierarchical clustering algorithm using minimum $\beta$ divergence based on the robust correlation matrix. It depends on the value of the tuning parameter $\beta$ and the initialization of parameters. Wessel N. van Wieringen[63] proposed an Partial Least Squares (PLS) algorithm for the prediction of survival time with microarray data. Their procedure, however, does not handle the censoring aspect of the survival data properly. PLS is a supervised dimension reduction technique which can be used to relate a response variable to the explanatory variables of the different PLS applied to regression problems without censoring, the method constructs the new components as mutually orthogonal linear combinations. Revathy and Amalraj [64] proposed Gene ranking techniques are T-Score, ANOVA, etc. techniques sometimes wrongly predict the rank when large database is used. And also displays the sparse representation using microarray gene expression data. WenHui Yang and Dao-Qing Dai[65] proposed an Mixed Clustering Algorithm is motivated by Agglomerative Hierarchical Clustering (AHC) which is one of the most popular clustering method in analyzing gene expression data. Sathiyabhama and Gopalan[66] saved that an Heuristic based Enhanced Correlation Search Technique (HECST) integrates the validation techniques into the clustering process so that it produces high quality clusters dynamically memory efficient data structure namely sparse matrices to store the gene expression profiles. Data produced by HECST tenders potential insight into gene function, molecular biological processes and regulatory mechanisms.

Table I: Class Discovery

\begin{tabular}{|c|c|c|c|c|}
\hline Author(s) & Technique(s) & Description & Advantage(s) & Disadvantage(s) \\
\hline $\begin{array}{l}\text { Amir Ben-Dory } \\
2004\end{array}$ & $\begin{array}{l}\text { Overabundance } \\
\text { Analysis }\end{array}$ & $\begin{array}{l}\text { It is used to display informative genes from the } \\
\text { expression data }\end{array}$ & $\begin{array}{l}\text { It is used to partitions data and } \\
\text { statistically significant } \\
\text { overabundance score. }\end{array}$ & $\begin{array}{l}\text { Overabundance of informative genes is an } \\
\text { indication of statistical significance, no } \\
\text { single gene is Bonferroni significant }\end{array}$ \\
\hline $\begin{array}{l}\text { Wee Cheng } \\
\text { Liew } 2005\end{array}$ & Pcluster Model & $\begin{array}{l}\text { Identify both additive and multiplicative biclusters from } \\
\text { gene expression data }\end{array}$ & $\begin{array}{l}\text { It can use for additive and } \\
\text { multiplicative biclusters. }\end{array}$ & Overlap the noise data. \\
\hline $\begin{array}{l}\text { Roberto Romero } \\
2006\end{array}$ & $\begin{array}{l}\text { Analysis of Variance } \\
\text { (ANOVA) }\end{array}$ & $\begin{array}{l}\text { Displays the number of Genes represented in array and } \\
\text { the order of tens of thousands }\end{array}$ & $\begin{array}{l}\text { It is also estimates of the } \\
\text { relative expression for each } \\
\text { gene. }\end{array}$ & Non parametric test to estimate the genes. \\
\hline $\begin{array}{l}\text { Hau-San Wong } \\
2007\end{array}$ & $\begin{array}{l}\text { Graph based } \\
\text { Consensus } \\
\text { Clustering }\end{array}$ & $\begin{array}{l}\text { It is also estimate the underlying classes of the samples } \\
\text { in microarray data, determine the number of classes in } \\
\text { microarray data }\end{array}$ & $\begin{array}{l}\text { Identifies the number of } \\
\text { classes in real cancer datasets }\end{array}$ & Randomly select the subset of the genes \\
\hline $\begin{array}{l}\text { Jian Pei et al., } \\
2008\end{array}$ & Maple & $\begin{array}{l}\text { It is used to display the maximal patterns and then } \\
\text { prunes the unnecessary branches }\end{array}$ & $\begin{array}{l}\text { PC plot visualization tool for } \\
\text { the biclusters }\end{array}$ & It could not find the negative correlations \\
\hline $\begin{array}{l}\text { Monti et.al., } \\
2010\end{array}$ & $\begin{array}{l}\text { Merged Consensus } \\
\text { Clustering }\end{array}$ & $\begin{array}{l}\text { It is used find the weighted averaging of consensus } \\
\text { matrices from clustering with different algorithms } \\
\text { and/or conditions while only merging results for the } \\
\text { same number of clusters }\end{array}$ & $\begin{array}{l}\text { It also displays the ' } \mathrm{k} \text { ' value } \\
\text { assessed by the resembling } \\
\text { procedure }\end{array}$ & $\begin{array}{l}\text { Equal weight is applied for the } \\
\text { combination of consensus matrices }\end{array}$ \\
\hline $\begin{array}{l}\text { Wang et.al., } \\
2011\end{array}$ & $\begin{array}{l}\text { Principal Component } \\
\text { Analysis (PCA) }\end{array}$ & $\begin{array}{l}\text { Experimental conditions are the variables, and the gene } \\
\text { expression measurements }\end{array}$ & $\begin{array}{l}\text { It is used to summarizing the } \\
\text { groups of genes }\end{array}$ & It can't visualize gene expression data \\
\hline $\begin{array}{l}\text { C.P.Chandran, } \\
2012\end{array}$ & Enhanced CTWC & $\begin{array}{l}\text { It is used to find the prediction of class discovery from } \\
\text { gene expression data and to generate bicluster seeds }\end{array}$ & $\begin{array}{l}\text { It is used to identify the } \\
\text { coherent patterns }\end{array}$ & It couldn't find to an enlarge seeds. \\
\hline
\end{tabular}

Table II: Coherent Biclusters

\begin{tabular}{|c|c|c|c|c|}
\hline Author(s) & Technique(s) & Description & Advantage(s) & Disadvantage(s) \\
\hline Sarmah 2002 & Pattern Clus & $\begin{array}{l}\text { Identify the groups of genes with } \\
\text { similar expression values }\end{array}$ & $\begin{array}{l}\text { It is compared with the better } \\
\text { results in terms of Z-score } \\
\text { measure of cluster validation. }\end{array}$ & $\begin{array}{l}\text { The regulation pattern on } 0,1 \text { and - } \\
1\end{array}$ \\
\hline $\begin{array}{l}\text { Bloch et.al., } \\
2004\end{array}$ & DCCA & $\begin{array}{l}\text { It is used to display the coherent value } \\
\text { as the similarity measure gene data }\end{array}$ & $\begin{array}{l}\text { It can use the Pearson's } \\
\text { Correlation Coefficient(PCC) }\end{array}$ & $\begin{array}{l}\text { Display the coherence measure as a } \\
\text { neuron. }\end{array}$ \\
\hline $\begin{array}{l}\text { Owen et.al., } \\
2004\end{array}$ & GR & $\begin{array}{l}\text { Display the co expressed genes from } \\
\text { large microarray dataset }\end{array}$ & It is a score based search & $\begin{array}{l}\text { GR first selects a subset of query } \\
\text { genes are strongly co-regulated. }\end{array}$ \\
\hline $\begin{array}{l}\text { Thangavel } \\
2005\end{array}$ & $\begin{array}{l}\text { Query Driven } \\
\text { Biclustering }\end{array}$ & $\begin{array}{l}\text { Identifies the functionality of rich } \\
\text { query gene. }\end{array}$ & It is a top down approach & $\begin{array}{l}\text { They used both single node deletion } \\
\text { methods in order to arrive one } \\
\text { biclusters at a time }\end{array}$ \\
\hline $\begin{array}{l}\text { Busy gain } \text { et.al., } \\
2006\end{array}$ & $\begin{array}{l}\text { Double Conjugated } \\
\text { Clustering }\end{array}$ & $\begin{array}{l}\text { Coherent biclusters are defined by } \\
\text { using multiplicative model }\end{array}$ & $\begin{array}{l}\text { Values are defined by } \\
\text { multiplicative model of the } \\
\text { coherent biclusters. }\end{array}$ & $\begin{array}{l}\text { It cannot be used on the additive } \\
\text { model }\end{array}$ \\
\hline $\begin{array}{l}\text { Dhollander } \\
\text { et.al., } 2007\end{array}$ & $\begin{array}{l}\text { Model-based Query- } \\
\text { Driven method }\end{array}$ & $\begin{array}{l}\text { QDB tool used to analyze the coherent } \\
\text { biclusters. }\end{array}$ & $\begin{array}{l}\text { It can be used on the pattern } \\
\text { matching }\end{array}$ & It is a complex correlation patterns. \\
\hline $\begin{array}{l}\text { Fei } \\
2008\end{array}$ & $\begin{array}{l}\text { Genetic Fuzzy } \\
\text { Biclustering } \\
\text { Algorithm }\end{array}$ & $\begin{array}{l}\text { Identify the coherent biclusters from } \\
\text { gene expression data. }\end{array}$ & $\begin{array}{l}\text { Fuzzy value coherent } \\
\text { biclusters. }\end{array}$ & $\begin{array}{l}\text { Objective function used to } \\
\text { minimize the fuzzy value coherent } \\
\text { biclusters. }\end{array}$ \\
\hline $\begin{array}{l}\text { Hu et.al., } \\
2008\end{array}$ & BEST & $\begin{array}{l}\text { Used to detect the co expression } \\
\text { profiles. }\end{array}$ & $\begin{array}{l}\text { It is based on gene expression } \\
\text { query algorithm. }\end{array}$ & Bayesian Model framework \\
\hline Tang et.al., 2009 & $\begin{array}{l}\text { Interrelated Two- } \\
\text { Way Clustering } \\
\text { Approach }\end{array}$ & $\begin{array}{l}\text { Analysis the gene expression matrix } \\
\text { from expression data }\end{array}$ & It can be executed dynamically. & More space complexity. \\
\hline $\begin{array}{l}\text { Kluged et.al., } \\
2009\end{array}$ & $\begin{array}{l}\text { Discover the } \\
\text { Coherent Biclusters }\end{array}$ & $\begin{array}{l}\text { The data matrix are integrating } \\
\text { biclustering of rows and columns with } \\
\text { normalization of the data matrix }\end{array}$ & $\begin{array}{l}\text { Display both additive and } \\
\text { multiplicative model. }\end{array}$ & Check board structures. \\
\hline $\begin{array}{l}\text { C.P.Chandran, } \\
2012\end{array}$ & Enhanced K-Mediods & Identify coherent patterns & $\begin{array}{l}\text { It is used to display the } \\
\text { centered node. }\end{array}$ & Need to specify the ' $K$ ' value. \\
\hline
\end{tabular}


Table III: Coregulated Biclusters

\begin{tabular}{|c|c|c|c|c|}
\hline Author (s) & Technique(s) & Description & Advantage(s) & Disadvantage(s) \\
\hline Cheng, 2002 & Bivisu & $\begin{array}{l}\text { Display and Visualize the } \\
\text { coregulated genes }\end{array}$ & $\begin{array}{l}\text { It is used to partition data on whole } \\
\text { set of genes or conditions. }\end{array}$ & $\begin{array}{l}\text { Genes which are co-regulated under } \\
\text { certain biological processes can be } \\
\text { identified }\end{array}$ \\
\hline $\begin{array}{l}\text { Remanding, } \\
2006\end{array}$ & Coregulated Model & $\begin{array}{l}\text { Discover the coregulated } \\
\text { genes }\end{array}$ & $\begin{array}{l}\text { Used to clear relationship between } \\
\text { network structures. }\end{array}$ & $\begin{array}{l}\text { Coregulated genes are similar } \\
\text { expression profile in certain interval }\end{array}$ \\
\hline Peter Waltman, 2006 & Multiple Species & $\begin{array}{l}\text { Used to identify the } \\
\text { conserved modules }\end{array}$ & $\begin{array}{l}\text { Conserved modules are grouped } \\
\text { together on the biologically } \\
\text { significant than expression. }\end{array}$ & $\begin{array}{l}\text { Co-regulated gene groups are lacking } \\
\text { detectable }\end{array}$ \\
\hline $\begin{array}{l}\mathrm{Xu} \\
2009\end{array}$ & Reg-Clust model & $\begin{array}{l}\text { Coherent clustering of gene } \\
\text { expression data called reg- } \\
\text { cluster }\end{array}$ & $\begin{array}{l}\text { Identify the shifting and scaling co } \\
\text { regulation patterns }\end{array}$ & $\begin{array}{l}\text { Detect a significant amount of } \\
\text { clusters }\end{array}$ \\
\hline $\begin{array}{l}\text { Bhattacharya and } \\
\text { Raja,2009 }\end{array}$ & $\begin{array}{l}\text { Bi-Correlation } \\
\text { Clustering } \\
\text { Algorithm }\end{array}$ & $\begin{array}{l}\text { diverse set of biclusters of } \\
\text { co- regulated genes }\end{array}$ & $\begin{array}{l}\text { High throughput sequencing } \\
\text { technology }\end{array}$ & Poor robustness against noisy data \\
\hline $\begin{array}{l}\text { David J. Reiss } \\
2009\end{array}$ & cMonkey & $\begin{array}{l}\text { Consists of various } \\
\text { functional } \\
\text { associations they are } \\
\text { denovo } \\
\text { detection of sequence motifs }\end{array}$ & Detects putative co-regulated genes & $\begin{array}{l}\text { regulatory network inference } \\
\text { procedures is used }\end{array}$ \\
\hline Zhang et.al., 2010 & CC-TSB & $\begin{array}{l}\text { It consists of two steps they } \\
\text { are deletion and insertion } \\
\text { procedure. }\end{array}$ & $\begin{array}{l}\text { Predicated number of biclusters with } \\
\text { contiguous columns }\end{array}$ & $\begin{array}{l}\text { Restricting Add/or remove } \\
\text { only columns }\end{array}$ \\
\hline Dharan 2010 & GRASP & $\begin{array}{l}\text { Starts from quality of the } \\
\text { biclusters from gene } \\
\text { expression matrix. }\end{array}$ & $\begin{array}{l}\text { Only the small biclusters seeds are } \\
\text { generated }\end{array}$ & $\begin{array}{l}\text { Seeds are enlarged by adding more } \\
\text { rows and columns }\end{array}$ \\
\hline Luonan Chen 2011 & $\begin{array}{l}\text { Temporal } \\
\text { biclustering } \\
\text { algorithm }\end{array}$ & $\begin{array}{l}\text { Used to analyze the time- } \\
\text { series gene expression data }\end{array}$ & $\begin{array}{l}\text { It is based on discretization } \\
\text { preprocessing and sequence } \\
\text { alignment. }\end{array}$ & $\begin{array}{l}\text { identify similar local expression } \\
\text { profiles }\end{array}$ \\
\hline C.P.Chandran,2012 & Enhanced Bimax & $\begin{array}{l}\text { Identify the Coregulated } \\
\text { Genes }\end{array}$ & It is used only an DNA Chips & Need not specify value on ' $K$ ' value. \\
\hline
\end{tabular}

Table IV: Correlated Biclusters

\begin{tabular}{|c|c|c|c|c|}
\hline Author(s) & Technique(s) & Description & Advantage(s) & Disadvantage(s) \\
\hline $\begin{array}{l}\text { Anukit Agra } \\
\text { Wall, } 2004\end{array}$ & $\begin{array}{l}\text { Dynamic Time- } \\
\text { Lagged correlation }\end{array}$ & $\begin{array}{l}\text { Preprocessing technique is } \\
\text { used to find the time laggrd } \\
\text { correlation. }\end{array}$ & $\begin{array}{l}\text { The correlation matrix reaction } \\
\text { pathway is used. }\end{array}$ & $\begin{array}{l}\text { Calculate time } \\
\text { correlation functions. }\end{array}$ \\
\hline Bryan, 2005 & $\begin{array}{l}\text { Evolutionary } \\
\text { Approaches }\end{array}$ & Find the fitness function & $\begin{array}{l}\text { To find maximal biclusters with } \\
\text { low Mean Squared Residue } \\
\text { (MSR) }\end{array}$ & $\begin{array}{l}\text { Lack of clarity and } \\
\text { energy }\end{array}$ \\
\hline $\begin{array}{l}\text { Remondini, } \\
2006\end{array}$ & $\begin{array}{l}\text { Correlation based } \\
\text { Model }\end{array}$ & $\begin{array}{l}\text { Pears on Correlation } \\
\text { Coefficient }(\mathrm{PCC}) \text { used to } \\
\text { have maximumvalue of } \\
\text { one and two variables }\end{array}$ & $\begin{array}{l}\text { Describes the particular type of } \\
\text { as s ociation between two genes. }\end{array}$ & $\begin{array}{l}\text { It is based on thenetwork } \\
\text { structure. }\end{array}$ \\
\hline Moclah, 2006 & $\begin{array}{l}\text { Robust Correlation } \\
\text { (RC) Technique }\end{array}$ & $\begin{array}{l}\text { Minimum the } \beta \text {-divergence } \\
\text { based on robust correlation } \\
\text { matrix }\end{array}$ & $\begin{array}{l}\mathrm{RC} \text { is its robustness and sub-pixel } \\
\text { accuracy }\end{array}$ & $\begin{array}{l}\text { Statistical } \\
\text { interdependence among } \\
\text { the filter coefficients }\end{array}$ \\
\hline Banka, 2006 & Spectralbiclustering & $\begin{array}{l}\text { Identify biclusters } \\
\text { structures from the input } \\
\text { data. }\end{array}$ & $\begin{array}{l}\text { Spectral approach for biclustering } \\
\text { as suming that the data matrix } \\
\text { contains a checkerboard structure } \\
\text { after normalization. }\end{array}$ & $\begin{array}{l}\text { Lack of interpretability } \\
\text { of basis vectors dueto } \\
\text { negative values }\end{array}$ \\
\hline Liu, 2006 & $\begin{array}{l}\text { Greedy Randomized } \\
\text { Adaptive } \\
\text { Search(GRASP) }\end{array}$ & $\begin{array}{l}\text { It is a heuristic method that } \\
\text { has shown to bevery } \\
\text { powerful in solving } \\
\text { combinatorial problems. }\end{array}$ & $\begin{array}{l}\text { Search strategies in which cost- } \\
\text { deteriorating neighborho od }\end{array}$ & $\begin{array}{l}\text { Dynamic allocation of } \\
\text { the random access } \\
\text { memory }\end{array}$ \\
\hline $\begin{array}{l}\text { Nurual Haque, } \\
2008\end{array}$ & $\begin{array}{l}\text { Non Linear } \\
\text { Correlation }\end{array}$ & $\begin{array}{l}\text { Displays the data on the } \\
\text { median correlation. }\end{array}$ & $\begin{array}{l}\text { It can be specify on linear } \\
\text { correlationmatrix. }\end{array}$ & $\begin{array}{l}\text { It cannot specify the } \\
\text { mode correlation. }\end{array}$ \\
\hline Divina,2008 & PlaidModel & $\begin{array}{l}\text { statistical modeling } \\
\text { approach which repres ents } \\
\text { the input matrix as a } \\
\text { superposition of layers }\end{array}$ & $\begin{array}{l}\text { Dynamical range of the output } \\
\text { firing rates }\end{array}$ & $\begin{array}{l}\text { End-stopping as } \\
\text { incorporatedmodels is } \\
\text { used to support simple } \\
\text { cell model }\end{array}$ \\
\hline $\begin{array}{l}\text { Nepomuceno, } \\
2009\end{array}$ & $\begin{array}{l}\text { Enumeration } \\
\text { Algorithm }\end{array}$ & $\begin{array}{l}\text { Enumeration algorithm } \\
\text { solves the } \\
\text { problem by generating a } \\
\text { sequence of circuit-free } \\
\text { graphs }\end{array}$ & $\begin{array}{l}\text { Enumeration algorithms used in } \\
\text { integer programming }\end{array}$ & $\begin{array}{l}\text { DPalgorithm for the } \\
\text { enumeration as the core } \\
\text { gradually is extended. }\end{array}$ \\
\hline $\begin{array}{l}\text { C.P.Chandran, } \\
2012\end{array}$ & Modified Bimax & $\begin{array}{l}\text { It is used to find the } \\
\text { Correlated Bicluster }\end{array}$ & $\begin{array}{l}\text { It can use the Pearson Correlation } \\
\text { Coefficient(PCC) }\end{array}$ & $\begin{array}{l}\text { Correlation coefficients } \\
\text { value is near } 1,0 \text {, and }-1 \text {. }\end{array}$ \\
\hline
\end{tabular}




\section{DISCUSSION}

Survey on biclustering approaches for GED deals with the four issues. Class Discovery approaches are applied on the several techniques. They are Pclust model, Analysis of Variance, Graph based consensus clustering, Merged consensus clustering, and the recent one is Enahced CTWC applied. Class discovery from gene expression data, dimensionality reduction with PCA to reduce the dataset without much loss of information. It also displays the Summarizing the groups of the genes and then cannot visualize the GED and then get the results on discover the entire pattern based biclustering. The existing pattern based biclustering are CE-Tree, Maple and Micro cluster. And the new pattern based biclustering are Hash based biclustering models are dynamically creating the space for new data elements. The Enhanced CTWC algorithm used to find the prediction of class discovery from gene expression data. It can be classified into two phases. In the first phase K-means algorithm used to generate the seeds. In the second phase are to enlarge the seeds.

Coherent bicluster approaches helps to many different techniques. They are DCCA, CTWC, Patternclus, Greedy algorithm, Query Driven biclustering, and temporal biclustering. It is used to analyse time-series from gene expression data. Coupled Two Way Clustering algorithm (CTWC) also performs one way clustering on the rows and columns of the data matrix using stable clusters of row as attributes for column clustering and vice-versa also gets the results on subsets of genes and the subsets of conditions and the significant to the gene clusters. A greedy algorithm repeatedly executes a search procedure which tries to maximize the biclusters based on examining local conditions, with the hope that the outcome will lead to a desired outcome for the global problem, gets the results on One-to-one relation between web users and pages of a web site is not appropriate because web users are not strictly interested in one category of web pages. And then identifies the coherent browsing pattern from the web usage data. In the recent algorithm, is Enhanced $\mathrm{K}$-mediods algorithm used to find the Coherent biclusters group of co-expressed genes exhibits a common expression pattern.

Coregulated bicluster approaches are used to find the techniques are bivisu, coregulated model, BCCA, CC-TSB, Reg-cluster model, cMonkey, multiple species and GRASP. GRASP happens in two phases. They are construction and local search. In the construction phase a feasible solution is developed iteratively by adding one element each time which will generate a feasible solution whose neighborhood will be searched until a local minimum is identified during the local search phase. The best solution is stored as the result. Correlated Pattern Biclusters (CPB), that identifies groups of genes highly correlated with a given reference gene in empirically defined subsets of samples. CPB involves two issues. They are mining datasets only to discover correlated patterns that contain the given reference gene, extension of the use of PCC in biclustering context. Gets the result also overlapping clusters and also captures the negative correlation.
Pearson Correlation Coefficient (PCC) then counts the number of times each gene co-occurs in the same cluster with the reference gene over all datasets. Get the results on positive as well as negative co-regulation between rows, commonly used in clustering gene expression data and capturing both shifting and scaling patterns. BCCA display a diverse set of biclusters of co-regulated genes over a subset of samples where all the genes in a bicluster have a similar change of expression pattern over the subset of samples. The genes in a bicluster have common transcription factor binding sites in the corresponding promoter sequences. Enahced Bimax algorithm used to find the Coregulated biclusters are also often functionally associated, and such $a$ priori known or precomputed associations can provide support for appropriately grouping genes. It is a measure of that describes a particular type of association between two genes. It is also the basis of several clustering methods.

Correlation Bicluster approaches helps to find deals with the techniques are Enumeration algorithm, Non-Linear correlation, Dynamic time-lagged correlation, Robust correlation, spectral biclustering, correlation based model and plaid model. Enumeration algorithms based on tree structure and it uses on evaluation function based on Spearman's Rank Correlation is a technique used to test the direction and strength of the relationship between two variables. Plaid Model is a statistical modeling approach which represents the input matrix as a superposition of layers where each layer corresponds to a bicluster.

Nonlinear correlation gets the results gene expression patterns more accurate clustering of genes, which in turn leads to better understanding of gene relationships and functions. Dynamic Time- Lagged Correlation Based Method (DTCBM) to learn the gene networks, which uses time-lagged correlation to find the potential gene interactions, and then uses a postprocessing stage to remove false gene interactions to common parents, and finally uses dynamic correlation thresholds for each gene to construct the gene network. Gets the result on correlation between gene expressions signals shifted in time, and therefore takes into consideration the multi time delay relationships among the genes.

\section{CONCLUSION}

This paper presented a survey on Biclustering approaches for GED providing an overview on what has been done. In this work identified some problems in Gene Expression Data are Class Discovery, Coherent, Correlated and Coregulated Biclusters. Based on the survey Class discovery approaches to identify coherent patterns known as scaling and shifting patterns, the PCA technique is applied. Coherent biclusters, the Genes involved in common processes are often coexpressed and the Temporal Biclustering algorithm deals with analyze the time series Gene expression data. 


\section{REFERENCES}

[1] H. Banka, S. Mitra., "Evolutionary biclustering of gene expression data", Proceedings of the 2nd international conference on Rough sets and knowledge technology, Vol.12, Pp. 284-291, 2007.

[2] Y. Luan and H. Li, "Clustering of time-course gene expression data using a mixed-effects model with B-splines", Bioinformatics, Vol. 19, Pp. 474-482, 2003.

[3] K. Bloch, "Evolutionary biclustering of gene expression data", 2nd International conference on Rough sets and knowledge technology, Vol.3, Pp. 284-291, 2007.

[4] H. Wang, and J. Yang, "Clustering by pattern similarity in large data sets", International Conference on Management of Data, Proceedings of the 2002 ACM SIGMOD International Conference on Management of Data, Vol.2, Pp. 394 - 405, 2007.

[5] Jain Pei "MaPle: A Fast Algorithm for Maximal Pattern based Clustering", IEEE International Conference on Data Mining, Vol. 1, Pp. 1-10, 2003.

[6] Lizhuang Zhao and Mohammed J. Zaki, "Micro Cluster: Efficient Deterministic Biclustering of Microarray Data", IEEE Intelligent Systems, Vol.1, Pp. 40-49, 2005.

[7] Wen-Hui Yang, Dao-Qing Dai, Hong Yan, "Finding Correlated Biclusters from Gene Expression Data, "IEEE Transactions on Knowledge and Data Engineering", Vol.2, Pp.1-15, 2010.

[8] Alan Wee-Chung Liew, "Identification of coherent patterns in gene expression data using an efficient biclustering algorithm and parallel coordinate visualization", BMC Bioinformatics, Vol. 9, Pp. 121- 130, 2008 .

[9] Jiun- Rung Chen "Clustering by pattern similarity in large data sets" International Conference on Management of Data, Proceedings of the 2002 ACM SIGMOD International Conference on Management of Data, Vol.1, Pp. 394 - 405, 2007.

[10] Amir Ben-Dory, "Class Discovery in Gene Expression Data", BMC Bioinformatics, Vol.1, Pp.1-8, 1999.

[11] Nir Friedmanz, "Overabundance Analysis and Class Discovery in Gene Expression Data", Molecular Biology, Vol.12, Pp.1-26, 2001.

[12] M. Gaasenbeek, "Molecular Classification of Cancer: Class Discovery and Class Prediction by Gene Expression Monitoring", BMC Bioinformatics, Vol.286, Pp.1-7, 1999.

[13] M. Bloch et al, "Biclustering of Gene Expression Data to discover a coherent patterns", Journal of Bio Data Mining, Vol.4,Pp.1-6, 2011.

[14] Jeff Solka, “ Gene Latent Class Discvoery”, Journal of Genomics, Vol.1,Pp.1-28, 2000.

[15] Nikhil Ranjan Pal, "Deriving meaningful rules from gene expression data for classification", Bioinformatics, Vol.21, Pp. 1-10, 2003.

[16] ALL/AML Cancer Classification by Gene Expression Data Using SVM and CSVM Approach, Genomics Informatics, Vol.11, Pp.237-239, 2000.

[17] Chun Tang, "Interactive Visualization and Analysis for Gene Expression Data", IEEE, Proceedings of the 35th Hawaii International Conference on System Sciences, Vol.35, Pp.256-261, 2002.

[18] Michael O'Connell, "Differential Expression, Class Discovery and Class Prediction using S-PLUS and S+ArrayAnalyzer", SIGKDD Explorations, Vol.5, Pp.38-48, 2009.

[19] Peng Qiu, "Simultaneous Class Discovery and Classification of Microarray Data Using Spectral Analysis", Journal of Computational Biology, Vol.16, Pp. 935-945, 2009.

[20] Tibshirani et. al,. Class Discovery in Acute Lymphoblastic Leukemia using Gene Expression Analysis, Bioinformatics, Vol.23, Pp.1-34, 2003.

[21] Bloch et al., Relational subgroup discovery for gene expression data mining, genomics, Vol.21, Pp.23-35, 2005.

[22] Tchagang, "A differential biclustering algorithm for comparative analysis of gene expression, 14th European Signal Processing Conference (EUSIPCO 2006), Florence, Italy, September 4-8, Vol.14, Pp.1-4, 2006.

[23] Biclustering of Gene Expression Data Based on Local Nearness, bioinformatics, Vol. 12, Pp. 123-126, 2009.

[24] Cesim Erten, "Biclustering Expression Data Based on Expanding Localized Substructures”, Computational Biology, Vol.23, Pp. 123-130, 2006.

[25] Anirban Mukhopadhyay, "On Biclustering of Gene Expression Data", Current Bioinformatics, Vol. 5, Pp:204-216,2010

[26] Gaurav Pandey, "An Association Analysis Approach to Biclustering”, ACM, Vol.10, Pp.1-9, 2009.
[27] Hua-Sheng Chiu, "Biclustering Gene Expression Data by Using Iterative Genetic Algorithm”, Genomics, Vol.12, Pp.1-3, 2009.

[28] Peter A. DiMaggio, "A network flow model for biclustering via optimal re-ordering of data matrices", Journal of Global Optimization, Vol.10, Pp.234-240, 2010

[29] Andre V. Carreiro, "Prognostic Prediction through Biclustering-Based Classification of Clinical Gene Expression Time Series", Journal of Integrative Bioinformatics, Vol. 8, Pp.175- 184, 2011

[30] Sanghamitra Bandyopadhyay, "A Novel Coherence Measure For Discovering Scaling Biclusters From Gene Expression Data", Journal of Bioinformatics and Computational Biology, Vol. 7, Pp. 853-868, 2009.

[31] S. Sambh., "Discovering of coherent biclusters in gene expression data", Journal of Biomed central, Vol.4, Pp.20-25, 2009.

[32] K. Bhattacharyya."Discovering an nontrivial biclusters from gene expression data", International Journal of Computer Applications, Vol.4, Pp.12-17, 2008.

[33] P. Valarmathie "Survey on Clustering algorithms for Microarray Gene Expression Data", European Journal of Scientific Research, Vol. 69, Pp.5-20, 2012.

[34] X. Fei "Fuzzy Biclustering for Microarray Gene Expression Data", IEEE, Vol.23, Pp. 545-551, 2008.

[35] C. Tang et. al, "DASS-GUI: a user interface for identification and analysis of significant patterns in non-sequential data", Journal of Biomed Central, vol. 26, Pp. 987-989, 2010.

[36] Y. Kluger et. al., "Spectral Biclustering of Microarray Data: Coclustering Genes and Conditions", Genome Research, Vol.13, Pp. 12-20, 2003.

[37] Busy gin, "Exploring Microarray Data with Correspondence Analysis", Bioinformatics, Vol.12, Pp.1-14, 2000.

[38] T. Dhollander et. al., "Query-driven module discovery in microarray data". Bioinformatics, Vol.4, Pp.201-216, 2007.

[39] A.B. Owen et. al., "A gene recommender algorithm to identify co expressed genes in C. elegant". Genome Res, Vol.13, Pp. 1828-1837, 2003.

[40] M. Hu and Z.S.Qin. "Query Large Scale Microarray Compendium Datasets using a Model- Based Bayesian Approach with Variable Selection”, PLoS ONE, Vol. 4, Pp. 4495- 4452, 2009.

[41] J. Bagyamani, K. Thangavel. "SIMBIC: Similarity Based Biclustering of Expression Data". Information Processing and Management Communications in Computer and Information Science, Vol. 70, Pp.437-441, 2010.

[42] J. Zhang "A Fast Algorithm for Maximal Pattern based Clustering", IEEE International Conference on Data Mining, Vol. 1, Pp. 12- 23, 2003

[43] K. Thangavel, R. Rathipriya, " Bottom up Biclustering Using One Leave out Correlation", Global Journal of Computer science and Technology, Vol.12, Pp.9-15,2011.

[44] K. Thangavel, R. Rathipriya, "Evolutionary Biclustering of Click stream Data", IJCSI International Journal of Computer Science ISSUES, Vol.8, Pp.341-348, 2011.

[45] Zhang et al., "Serial analysis of gene expression", Bioinformatics, Vol.21, Pp.1-10,2000.

[46] David J. Reiss, "Reconstructing Biological network from data", BMC Biomed Central, Vol.12, Pp.20-29,2009.

[47] X. Xu, "Mining Shifting-and-Scaling Co-Regulation Patterns on Gene Expression Profiles", Bioinformatics, Vol.1, Pp.1-10, 2009.

[48] S. Dharan and S. Achuthsankar, "Biclustering of gene expression data using reactive greedy randomized adaptive search procedure", Biomed Central, Vol.10, Pp. 13-19, 2009

[49] A. Bhattacharya and K. Raja, "Bi-correlation clustering algorithm for determining a set of co-regulated genes", Bioinformatics, vol. 25, pp. 2795-2801, 2009.

[50] Zhang and Zhan, "Finding Correlated Biclusters from Gene Expression Data," IEEE Transactions on Knowledge and Data Engineering, Vol. 23, Pp. 12-24, 2010.

[51] Y. Cheng, G.M Church, "Biclustering of expression data". International Conference on Intelligent Systems for Molecular Biology, Vol.12, Pp.93-103, 2000

[52] Peter Waltman, "Multiple species Integrative Biclustering", Genome Biology, Vol.11, Pp.1-10,2010.

[53] Remondini, "Gene Expression Patterns", Elsevier, Vol.12, Pp.12-20, 2002.

[54] Karen Bloch and Gonzalo Acre "Analyzing time series gene expression data", Bioinformatics, Vol. 20, Pp. 2493-2503, 2004. 
[55] Anush Mittal, "Bayesian Network Technologies applications and graph models", Journal of Genome Biology, Vol.3, Pp.12-20,2004.

[56] Nurual Haque Moclah, "Biclustering of Gene Expression Data by Correlation-Based Scatter Search", Journal of Biomed Central, Vol.4, Pp.212-220, 2011.

[57] Lindl "Could correlation methods be used to derive genetic association networks", Genomics, Vol.1, Pp.12-24, 2003.

[58] Peter Larsen and Eyad Almasri, "Correlated Discretized Expression Score: A Method for Identifying Gene Interaction Networks from Time Course Microarray Expression Data", IEEE, Vol.4, Pp.5842-5844, 2006.

[59] Ankit Agrawal, and Ankush Mittal, "A Dynamic Time-Lagged Correlation based Method to Learn Multi-Time Delay Gene Networks", World Academy of Science, Engineering and Technology, Vol. 9, Pp. 167-175, 2005.

[60] Juan A Nepomuceno and Alicia Troncoso, "Biclustering of Gene Expression Data by Correlation-Based Scatter Search", Bio Data Mining, Vol.4, Pp.1-17, 2011.

[61] Feng He and An-Ping Zeng, "In search of functional association from time-series microarray data based on the change trend and level of gene expression", BMC Bioinformatics, Vol.7, Pp.1-15,2006.

[62] Nurul Haque Mollah, "Robust Hierarchical Clustering for Gene Expression Data Analysis", Biostatistics, Vol.7, Pp.1-5, 2006.

[63] Wessel N. Van Wieringen, "Survival prediction using gene expression data: a review and comparison", Elsevier, Vol.23, Pp.1-28, 2008.

[64] N. Revathy and Dr. R. Amalraj, "Accurate Cancer Classification using Expressions of Very few Genes", International Journal of Computer Applications, Vol.14, Pp.19-22, 2011.

[65] Wen-Hui Yang and Dao-Qing Dai, "Finding Correlated Biclusters from Gene Expression Data", IEEE Transactions On Knowledge And Data Engineering, Vol. 23, Pp. 567- 583, 2011. 